\title{
PHOTOGRAMMETRY AND LASER SCANNING FOR THE EARTH SCIENCES- WORKING GROUP V6
}

\author{
J.H. Chandler ${ }^{\mathrm{a},{ }^{*}}$, S.J. Buckley ${ }^{\mathrm{b}}$, D. Rieke-Zapp ${ }^{\mathrm{c}}$, and R. Wackrow ${ }^{\mathrm{a}}$ \\ ${ }^{a}$ Dept. Civil and Building Engineering, Loughborough University, LE11 3TU, UK - J.H.Chandler@lboro.ac.uk \\ ${ }^{\mathrm{b}}$ University CIPR - University of Bergen, Postboks 7810, N-5020 Bergen, Norway. \\ ${ }^{\mathrm{c}}$ Universität Bern, Institut für Geologie, Baltzerstrasse 1+3, 3012 Bern, Switzerland.
}

\section{Commission V, WG V6}

KEY WORDS: Geomorphology, Environment, Geology, Geography, Cooperation, Landscape, Change, Surface

\begin{abstract}
:
With the UK gaining responsibility for Commission V at the Beijing Congress in 2008, there was an opportunity to create a new working group focusing on earth science applications at close range. The earth science community has had a long tradition of using close range photogrammetry, and more recently laser scanning, and such opportunities have not been fully recognised by ISPRS in the past. Formation of a new ISPRS Working Group helps to bridge this gap and promotes the skills of ISPRS members more widely. The purpose of this paper is to justify the creation of Working Group V6 and identify some of the activities conducted over the last four years. In particular, reference will be made to the various technical sessions which have been organised and supported across the world, the first resulting in a Special Issue of The Photogrammetric Record published in September 2010. In addition, Working Group V6 has been responsible for the creation of two freely available guidance documents entitled "tips for the effective use of digital close range photogrammetry and terrestrial laser scanning". The former focuses on close range digital photogrammetry and has developed through several iterations with input from both academic and industrial users from around the world. For this reason it should be of distinct value to new and perhaps non-expert users interested in using photogrammetry for earth science applications.
\end{abstract}

The paper includes a discussion which considers whether the initial four years of activity have been successful. A superficial assessment based upon the number of members attracted worldwide would suggest that this has indeed been the case. A deeper comparison between proposed activities and those actually achieved suggest some discrepancy, which is perhaps inevitable as Working Group Officers clearly have other responsibilities. However, examination of papers published in the earth surface journals reveal high incidence of photogrammetry and laser scanning appearing in recent work. This should encourage members of Working Group V6 in future activities and collaborations.

\section{INTRODUCTION}

The Beijing Congress (2008) will hopefully represent a key turning point for those combining an interest in photogrammetry and laser scanning with the earth sciences, particularly at close range. Previously, such an interest was inevitably diluted between commissions (most notably $\mathrm{V}$ and VII) and hence frequently falling between the activities of various commission working groups. The purpose of this paper is to identify the need and outline the activities of this fledgling Working Group since its inception in 2008. This brief review will provide V6 with a firm foundation for further development and will help nurture the large number of physical geographers and earth scientists who are routinely using "our" techniques. Following a review of past work, the formation and justification for the creation of Working Group V6 is described. This is followed by a brief review of V6 activities between 2008 and 2012.

\section{PAST ACTIVITIES- WITHIN ISPRS AND BEYOND!}

It can be argued that the tradition of using photogrammetry in earth science is as old as photogrammetry itself. Notably,
Finsterwalder helped to develop the foundations of analytical photogrammetry through the mapping of Alpine glaciers in the late 19th century. During the 20th century, a range of studies demonstrated the potential of photogrammetry, and Lane et al (1993) provides a useful review. Important application areas can be identified, including: slope and landslide dynamics (e.g. Wickens and Barton, 1971; Fraser, 1983; Atkinson, 1980), glacial change (Stirling et al, 1982; Small et al, 1984) and in river channel change. Application of photogrammetry to fluvial studies has been particularly successful area with Collins and Moon (1979) measuring stream bank erosion and Welch and Jordan (1983) provided an early account of using photogrammetry to capture digital terrain models representing real riverbeds. This latter project determined both volumetric and morphological change using DEM differencing methods using repeat surveys. In geology, Rieke-Zapp et al. (2009) used consumer grade cameras and a simple field control setup for outcrop measurement.

The number of cited applications using photogrammetry in the earth science field has grown rapidly in more recent times as imaging software technologies associated with digital photogrammetry have evolved. Software originally focused on traditional aerial imagery from a vertical perspective, but with 
some adaption such software proved adept at processing close range imagery acquired using consumer grade digital cameras, even from an oblique perspective (Chandler, 1999; Chandler et al; 2002). Bird et al (2010) provides a recent account on this evolution, with a particular focus on the measurement and modelling of riverbeds, an area where the use of photogrammetry has become almost routine. Related work has developed for application in the more controlled laboratory flume environment (e.g. Stojic, et al, 1998; Rieke-Zapp and Nearing, 2005). Here the potential of consumer grade cameras and close range photogrammetry for measuring change for both soil science and fluvial processes has proved most advantageous. The increasing resolution and ever reducing costs of digital cameras has continually improved the resolution of captured morphological data. In addition, software is now available to specifically process close range imagery (i.e. PhotoModeler Scanner, 2011). Camera calibration and measurement of images using target recognition has been automated fully, allowing projects to be processed ever more rapidly and conveniently. Some software is also now freely available, such as Autodesk's 123-D Catch, which can achieve medium accuracy results easily, even for the totally novice user (Chandler and Fryer, 2011).

The introduction of terrestrial laser scanners in the late 1990s, and their continued evolvement through to the present day, has provided further stimulus for earth scientists to make use of geomatics techniques. The use of an active sensor to directly obtain 3D measurements has provided a useful shortcut and therefore an alternative to digital photogrammetry, particularly for large and complex scenes. The desired product of photogrammetric processing is often a terrain surface model. This can be achieved directly using laser scanning, and for laser scanning projects, integration with imagery is often crucial for adding interpretive value in the form of colour and texture. Indeed, a noticeable trend is the desirability of value-added laser point clouds, where the 3D information is enhanced with RGB (red, green, blue) colour, laser intensity, or multi- or hyperspectral imagery (Franceschi et al., 2009; Burton et al., 2011; Kurz et al., 2011).

Laser scanning is in use in many disciplines within the earth sciences, from vegetation studies and forestry to geomorphology, hydrology and coastal change (an introduction can be found in Heritage and Large, 2009). Geology is one discipline that has adopted laser scanning as a standard method for field research studies and in engineering geology (e.g. Bellian et al., 2005; Buckley et al., 2008; Sturznegger and Stead, 2009).

Earth science has had a long-term association with ISPRS, although Commission titles has never made this explicitly obvious to non- photogrammetrists. The current Commissions have evolved since 1992 (Washington), increasing from 7 to 8 in 2004 following the Istanbul Congress. However this evolution has been gradual, with the first six Commissions remaining very similar in both title and scope since 1992. "Earth science" has never been a traditional keyword within the
ISPRS list but "geomorphology" always has and "geology" has made frequent appearances in the Proceedings. These two keywords provide a useful surrogate search term for a brief review. This search reveals just 8, 15 and 15 occurrences in the proceedings in 2000 (Amsterdam); 2004 (Istanbul) and 2008 (Beijing) respectively, distributed evenly within Commissions $\mathrm{V}$ and VII. Despite this seemingly moderate interest, a brief search through the Proceedings reveals far greater incidence of material of relevance to the earth sciences and the activities of WG V6. Other relevant keywords can be identified, including: glaciology, hydrology, landslides, snow/ice, soil and forestry, and a more inclusive search suggests far greater activity within the earth science arena. Indeed, in 2004 and 2008, these keywords contribute to a total of 38 and 22 papers presented respectively, a sizeable interest.

\section{JUSTIFICATION AND FORMATION}

The U.K.'s bid to host Commission V was overwhelmingly supported at the Beijing Congress under the preferred commission name of "close range sensing: analysis and applications", which describes the activities of Commission V. Between 2004-8, six working groups had operated officially, but working group V6 (medical image analysis, human emotion and body measurement) had foundered, mainly because it had proven difficult to involve medical practitioners in ISPRS activities. Only 15 abstracts had been received for Beijing and therefore a new direction was sought.

The first author of this paper had been successful in collaborating with earth scientists, particularly physical geographers and geomorphologists, since 1988. Such scientists had a real need for accurate spatial data to represent landforms and natural objects and to quantify how these evolved spatially as earth surface processes operated. Initially, all aspects of spatial data acquisition had been my responsibility, but as photogrammetric software systems developed and cheaper consumer grade digital cameras became available, a new generation of geographers became increasingly involved in data acquisition themselves. My activities shifted to a training and more advisory role, typically camera calibration or extending the opportunities of spatial measurement through using an oblique perspective (Chandler et al, 2002) or other image configurations (Wackrow and Chandler, 2008). Throughout this 20 year period of collaborating with a wide variety of earth scientists, several trends developed and became apparent:

- $\quad$ There was and remains a real need to develop expertise in close range spatial measurement within the earth sciences. Indeed, anecdotal evidence suggests that many photogrammetrists working in academia have become involved in such applications;

- Many geographers were using photogrammetric methods without a full understanding of constraints and limitations. This has occasionally caused frustration, either through poor results and over expectation of what was practicable;

- The marketing of software and systems, as "easy-to-use" has tended to increase the number of disappointed users. This trend was further exacerbated with the introduction of 
laser scanning hardware which appeared to offer XYZ coordinates with minimal expertise being required;

- The ISPRS Congress did not provide an obvious opportunity for publishing applications and lessons learnt, as no working group provided a natural focus for earth surface applications. Indeed my own earth science related congress papers (Stirling et al, 1992; Chandler et al, 1996; Chandler et al, 2000; Walstra et al, 2004 and Chandler et $\mathrm{al}, 2008$ ) had to be presented across many working groups and commissions, and generally to a disinterested audience because scales of interest varied so greatly;

- Finally, it was apparent that the ISPRS community itself did not recognise fully the opportunity of engaging with the new and growing earth science community.

These trends therefore created a desire to instigate some shift of focus within ISPRS and the Beijing Congress provided this opportunity.

Once the responsible member country for Commission V had been decided upon in Beijing, a series of open meetings provided the opportunity to develop and organise the various working groups. Discussions between the authors of this paper identified the opportunity for earth science, initially encompassing the activities of those involved in medical photogrammetry. Indeed, in its initial form a working group title of "bio and enviromorphological applications" was developed and presented to ISPRS Council. This was initially rejected in Beijing, with the suggestion to remove the medical area completely, so providing a tighter focus. Following various iterations of title including: "natural morphology at close range"; the title "close range morphological measurement for the earth sciences" was agreed upon and adopted finally in October 2008.

\section{ACTIVITIES SINCE INCEPTION}

Immediately after official acceptance, an early task was to announce and publicise the existence of working group V6 and its terms of reference. Prior to inception, the working group officers had already obtained the interest and support of 35 members worldwide, which provided an encouraging initial starting point.

\subsection{Website development}

The working group V6 website (Figure $\mathbf{1}$ and accessible electronically from: http://isprsv6.lboro.ac.uk/) provided an important early source of information and vehicle for dissemination. Through domain name registration and a variety of electronic mailing lists and personal contacts worldwide, interest was generated and membership rose to approximately 70 in early 2009, just two months after formation. The website was typically receiving 10 hits per day, clearly providing a key method of keeping users informed of intentions and activities. This is an important role which it continues to fulfil today.

\subsection{Worldwide conference sessions}

Working group officers are volunteers and need to accommodate V6 activities with other academic or commercial activities. This creates a very real constraint on what is possible and it was felt best to focus on organising sessions at a variety of international conferences. The first open meeting took place on 10th September, 2009 as part of the RSPSoc 2009 conference, held at Leicester, United Kingdom. Here seven papers were presented by members of the working group, across two dedicated technical sessions. Presenters were truly international, travelling from Switzerland, Norway, Ethiopia, Italy, Austria and even Australia! Attendance was high, with between 30 to 45 individuals attending both technical sessions. An early benefit was the suggestion of putting the best papers into a Special Issue of the Photogrammetric Record (Section 4.3).

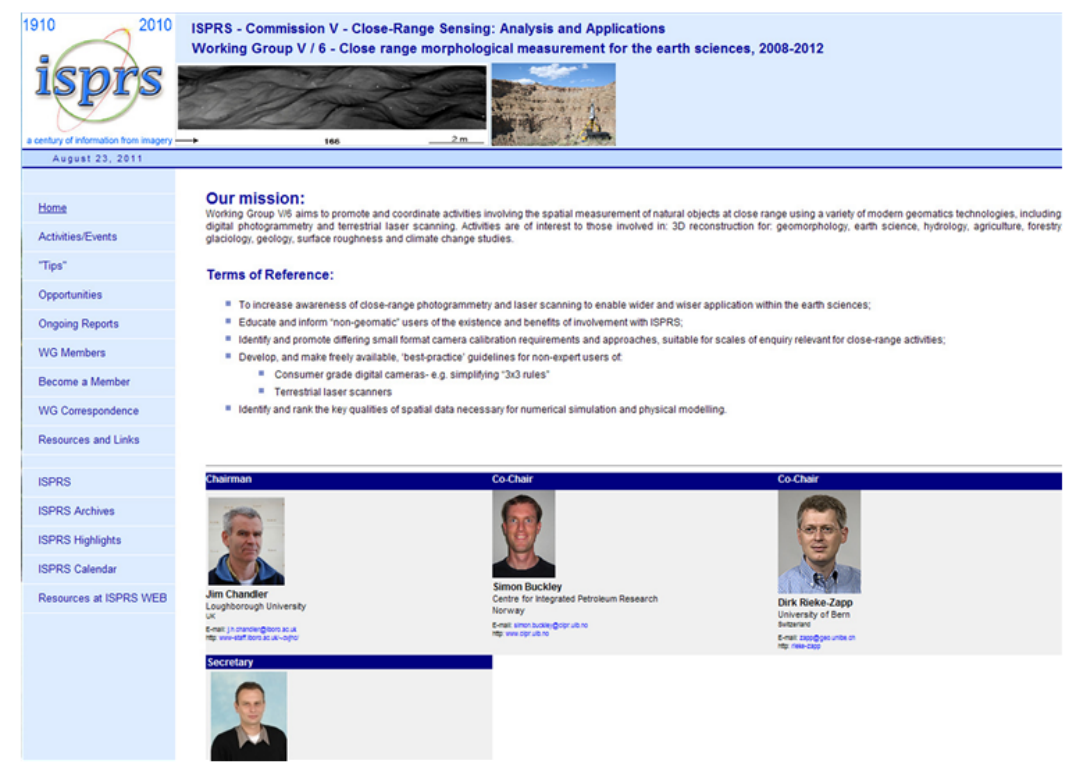

Figure 1- Working Group V6 website

The working group organised two technical sessions in 2010. Dirk Rieke-Zapp (co-chair) coordinated a session at the General Assembly of the European Geosciences Union in Vienna in early May, entitled "High Definition Topography- Data Acquisition and Analysis". Simon Buckley (co-chair) coordinated the working group V6 session for the Midterm Commission V Symposium, held in Newcastle, UK in June 2010.

The working group coordinated two technical sessions in 2011. Dirk Rieke-Zapp (co-chair) again co-convened a full day session at the General Assembly of the European Geosciences Union in Vienna in April 2011, entitled "Digital Landscapes: Acquisition (close range measurement and laser scanning) to Quantitative Interrogation". Jim Chandler (chair) also convened a V6 session at the Association of American Geographers 
(AAG) Annual Conference. This was held in April 2011 in Seattle, USA, where it was felt that it was important to spread the ISPRS V6 message. Prior, all V6 sessions had been held in Europe and it was believed important to nurture some interest amongst the North American community.

Providing opportunities for earth scientists and spatial measurement scientists to present remains an important activity for V6 Officers. Two sessions are currently planned for this Melbourne Congress, one being a "Special Session" entitled "Morphological Change Detection" and is being held in collaboration with ISPRS WG IV/8. It is pleasing to report that James Dietrich, an American member of WG V6, coordinated the second V6 session at the AAG Annual Conference, held in New York in February 2012. In addition, a further session was held at the EGU in April, entitled "high-definition topography: data acquisition, modelling, interpretation”. This attracted no less than 12 oral and 22 poster presentations.

\subsection{Special Issue of The Photogrammetric Record}

One particularly important and tangible output from Working Group V6 has been the Special Issue of the Photogrammetric Record (http://onlinelibrary.wiley.com/doi/10.1111/phor. 2010.25.issue-131/issuetoc), which consisted entirely of papers by members presented at the V6 session at RSPSoc 2009. All five papers were peer-reviewed and provide a useful illustration of the diversity of technical problems which our members are addressing.
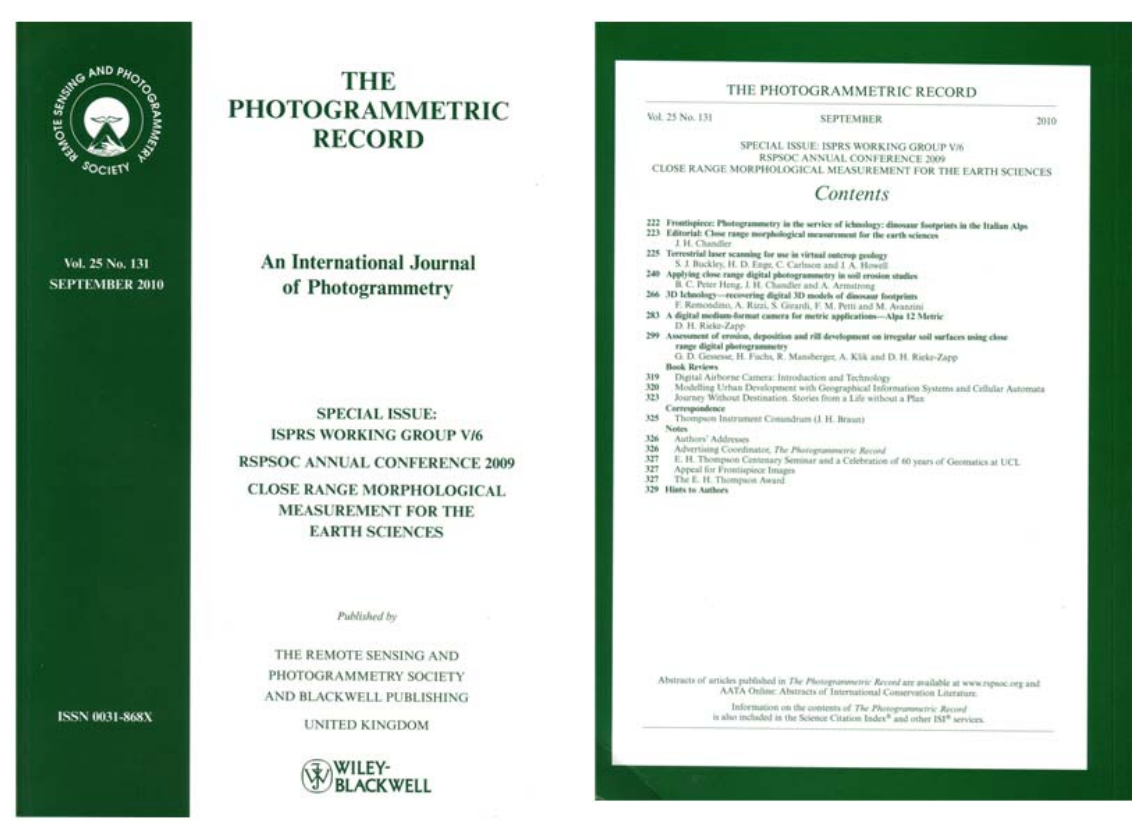

Figure 2 Special Issue of The Photogrammetric Record to measure natural surfaces. Indeed, a forceful example was the unfortunate Ph.D. student who contacted Loughborough University a week before embarking on a low level, small format aerial campaign to capture a small river system in Spain. She had no experience of ever doing such work and neither did her supervisor! Basic issues concerning size and distribution of control points and camera calibration were all-new issues to this particular research team! This unfortunate experience prompted the first author to draft and publish a basic guidance document (Chandler, 1999). This included recommendations for effective application of automated digital photogrammetry, particularly focused upon DEM generation. Once the working group became established in 2008, it seemed appropriate to update and extend this basic guidance. This provided the opportunity to seek input from members of the working group, and allow the production of a more definitive document based upon wider experience. The first draft was developed over the summer of 2009, mainly using input from the working group officers and authors of this paper. An additional document focusing on laser scanning guidance was also generated and both were made freely available via the working group website (Figure 1). Favourable comments and suggestions were received during the subsequent year, consequently a second draft of the "photogrammetry tips" document was finalised in September 2010. It was particularly pleasing to receive input from industrialists using the techniques commercially, notably: Marco Tuomien, (Datapix Pty Ltd, Australia) and Stephen Bird (Fluvial Systems Research Inc., Canada).

\section{THE TIPS DOCUMENT}

\subsection{Creation and contributions}

Previous collaborative experience with the earth science community had demonstrated a need to provide basic training and advice for those about to use close range photogrammetry

\subsection{Key points}

Space prevents a full description of contents and the tips documents remain available electronically from: http://isprsv6.lboro.ac.uk/ tips.html. However, important sections within the close range digital photogrammetry document include: camera selection and camera calibration guide, and the importance of providing control in the object space, both for restitution and providing independent checks. Other sections focus upon data-processing and image configurations which can reduce the importance of an accurate camera lens model (Wackrow and Chandler, 2008). The document is only 10 pages in length and therefore provides readers with an easy and early indication of some of the issues that need to be considered. It may put some users off using the techniques but this is perhaps better than embarking on an ambitious campaign and failing. In such a situation, blame would tend to be focused on the technique, not the ill informed user! Since drafting, the author has become aware of an alternative document, which fulfils a similar role, compiled by the Bureau of Land Management in Colorado, USA (BLM, 2008). This provides an excellent and more pictorial explanation, describing photogrammetric 
workflow and includes three case studies focused on: change detection, integration of multiscale imagery and the recording of rock art. The appendices also provide useful guidance, particularly aimed at the first-time user.

\section{DISCUSSION}

Working Group V6 has now been in operation for almost 4 years and it is appropriate to ask whether success has been achieved and if it should continue in its current form. We can certainly cite the existence of 96 worldwide members currently. This is the highest number of members within any of the six working groups associated with Commission $\mathrm{V}$, and to establish that number shortly after formation has to be considered an impressive start. However, this defines "success" using a somewhat superficial measure. It is perhaps more useful to address the question by relating activity to the original terms of reference drafted in November 2008 (Figure 1) and repeated here for convenience:

1. To increase awareness of close-range photogrammetry and laser scanning to enable wider and wiser application within the earth sciences;

2. Educate and inform "non-geomatic" users of the existence and benefits of involvement with ISPRS;

3. Identify and promote differing small format camera calibration requirements and approaches, suitable for scales of enquiry relevant for close-range activities;

4. Develop, and make freely available, 'best-practice' guidelines for non-expert users of consumer grade digital cameras and terrestrial laser scanners;

5. Identify and rank the key qualities of spatial data necessary for numerical simulation and physical modelling.

Arguably, terms of reference number 1,2 and 4 have been addressed through a combination of conference sessions (Section 4.2), the Special Issue of The Photogrammetric Record (Section 4.3) and production of the tips documents (Section 5). Awareness of close range photogrammetry and laser scanning techniques must have been raised and certainly more earth scientists will now be aware of ISPRS activities. However, it is very difficult to really demonstrate exactly what the influence has been, particularly over such a short time period. In an attempt to examine the prevalence of photogrammetry and terrestrial laser scanning in the earth science community, the Web of Science (ISI, 2011) database was searched for the two keywords "photogrammetry" and "terrestrial laser scanning" using a small sample of earth science journals (Table 1).

\begin{tabular}{|l|c|c|}
\hline Journal title & $\begin{array}{c}\text { Photo- } \\
\text { grammetry }\end{array}$ & $\begin{array}{c}\text { Terrestrial } \\
\text { laser scanning }\end{array}$ \\
\hline $\begin{array}{l}\text { Earth surface processes and } \\
\text { landforms }\end{array}$ & 49 & 7 \\
\hline Geomorphology & 27 & 11 \\
\hline Catena & 17 & 7 \\
\hline Engineering geology & 11 & 2 \\
\hline Journal of glaciology & 11 & 1 \\
\hline Water resources research & 9 & 2 \\
\hline Progress in phys. geography & 5 & 1 \\
\hline Journal of hydraulic research & 3 & 1 \\
\hline Sedimentology & 2 & 1 \\
\hline
\end{tabular}

Table 1 Incidence of photogrammetry and terrestrial laser scanning in earth science journals

This is simplistic but demonstrates that photogrammetry and terrestrial laser scanning has and continues to be actively employed within the earth science community, with photogrammetry being 4 to 5 times more prevalent than terrestrial laser scanning. However, this does not reveal engagement with members of ISPRS. Most scientists prefer to be independent and will attempt to solve difficulties, rather than seeking assistance. Earth science engagement with the ISPRS community will only occur if there is some clear benefit to be accrued. It is perhaps important that members of WG V6, both now and in the future, continue to demonstrate that collaboration is often a key component to successful research outcomes.

Terms of reference 3 and 5 have not been addressed fully. In retrospect, they were overly ambitious and although remaining worthy should perhaps be omitted between 2012-16. This is of course presuming that WG V6 continues in its current form, which is dependent upon discussions being held here in Melbourne!

\section{CONCLUSION}

This paper has described the reasons for the formation of ISPRS V6 and outlined its key objectives. Notable outputs during the UK tenancy have included involvement at a variety of conferences across the world and a Special Issue of The Photogrammetric Record. Development of a "tips" document has provided the wider earth science community with a freely available good practice guide, which combines the wide knowledge and experience of the working group.

\section{ACKNOWLEDGEMENTS}

None of the work described could have been possible without the efforts of all those associated with Working Group V6, which is duly acknowledged.

\section{REFERENCES}

Atkinson, K. B.., 1980. Developments in close range photogrammetry. London: Applied Science, pp. 222.

Bird, S., Hogan, D. and Schwab, J. 2010, Photogrammetric monitoring of small streams under a riparian forest canopy. Earth Surface Processes and Landforms, 35, pp. 952-970.

BLM, 2008. Aerial and Close-Range Photogrammetric Technology Technical Note 428. U.S. Department of the Interior, Bureau of Land. Management, National Operations Center, Denver, Colorado. pp. 42. BLM/OC/ST-08/001+9162.

Bellian, J. A., Kerans, C. and Jennette, D. C., 2005. Digital outcrop models: applications of terrestrial scanning LIDAR technology in stratigraphic modeling. Journal of Sedimentary Research, 75(2), pp. 166-176.

Buckley, S. J., Howell, J. A., Enge, H. D. and Kurz, T. H., 2008. Terrestrial laser scanning in geology: data acquisition, 
processing and accuracy considerations. Journal of the Geological Society, 165(3), pp. 625-638.

Burton, D., Dunlap, D. B., Wood, L. J. and Flaig, P. P., 2011. Lidar intensity as a remote sensor of rock properties. Journal of Sedimentary Research, 81(5-6), pp. 339-347.

Chandler, J. H., Ashmore, P., Paola, C., Gooch. M. J. and Varkaris, F., 2002. Monitoring river channel change using terrestrial oblique digital imagery and automated digital photogrammetry. Annals of the Association of American Geographers, 92(4), pp. 631-644.

Chandler, J.H., 1999. Effective application of automated digital photogrammetry for geomorphological research, Earth Surface Processes and Landforms, 24, pp. 51-63.

Chandler, J.H., Lane, S.N. and Ashmore, P., 2000. Measuring river-bed and flume morphology and parameterising bed roughness with a Kodak DCS460 digital camera, International Archives of Photogrammetry and Remote Sensing, Amsterdam, Netherlands, Vol. XIX Part B6, pp. 250-257.

Chandler, J.H., Lane, S.N. and Richards, K.S., 1996. The Determination of Water Surface Morphology at River Channel Conferences Using Automated Digital Photogrammetry and Their Consequent Use in Numerical Flow Modelling, International Archives of Photogrammetry and Remote Sensing, Vienna, Austria, Vol. XXXI Part B7, pp. 99-104.

Chandler, J.H., Wackrow, R., Sun, X., Shiono, K. and Rameshwaran, P., 2008. Measuring a dynamic and flooding river surface by close range photogrammetry, International Archives of the Photogrammetry, Remote Sensing and Spatial Information Science, Beijing, China, Vol. XXXVII Part B8, pp. 211-216.

Chandler, J.H. and Fryer, J., 2011. Accuracy of Autodesk 123-D Catch? http://www-

staff.lboro.ac.uk/ cvjhc/OtherFiles/Accuracy\%20of\%20123DC atch.htm, accessed 5th December, 2011.

Collins, S. H. and Moon, G. C., 1979. Stereo metric measurement of stream bank erosion. Photogrammetric Engineering and Remote Sensing, 45 (2), pp. 183-190.

Fraser, C. S., 1983. Photogrammetric monitoring of Turtle Mountain: a feasibility study. Photogrammetric Engineering and Remote Sensing, 49 (11): pp. 1551-9.

Franceschi, M., Teza, G., Preto, N, Pesci, A, Galgaro, A. and Girardi, S., 2009. Discrimination between marls and limestones using intensity data from terrestrial laser scanner. ISPRS Journal of Photogrammetry and Remote Sensing, 64(6), pp. 522-528.

Heritage, G.L. and Large, A.R.G., 2009. Laser Scanning for the Environmental Sciences. Wiley-Blackwell, Chichester: pp278.

ISI, 2011. The ISI Web of knowledge.

http://www.webofknowledge.com/, accessed 18th Oct. 2011.

Kurz,. T. H., Buckley,. S. J., Howell,. J. A. and Schneider, D., 2011. Integration of panoramic hyperspectral imaging with terrestrial lidar data. Photogrammetric Record, 26, pp. 212-228.

Lane, S. N., Richards, K. S. and Chandler, J. H., 1993.

Developments in photogrammetry- the geomorphological potential. Progress in Physical Geography, 17 (3) , pp. 306328.

PhotoModeler Scanner, 2011. Eos Systems Inc. http://www.photomodeler.com/, accessed 18th October 2011.

Rieke-Zapp, D. H. and Nearing, M. A., 2005. Digital close range photogrammetry for measurement of soil erosion, Photogrammetric Record, 20 (109), pp. 69-87.

Rieke-Zapp, D. H., Rosenbauer, R. and Schlunegger, F., 2009. A photogrammetric surveying method for field applications, Photogrammetric Record, 24(125) , pp. 5-22.

Small, R. J., Beecroft, I. R. and Stirling, D. M., 1984. Rates of deposition on lateral moraine embankments, Glacier de Tsidjions Nouve, Valais Suntgaland. Journal of Glaciology, 30(106), pp. 272-281.

Stirling, D.M., Chandler, J.H. and Clark, J.S., 1992. Monitoring one of Europe's largest retaining walls using oblique aerial photography, International Archives of Photogrammetry and Remote Sensing, Washington, USA, Vol. XXIX Part B5, pp. 701-708.

Stojic, M., Chandler, J. H., Ashmore, P., Luce, J., 1998. The assessment of sediment transport rates by automated digital photogrammetry. Photogrammetric Engineering and Remote Sensing 64, pp. 387-395.

Sturznegger, M. and Stead, D., 2009. Quantifying discontinuity orientation and persistence on high mountain rock slopes and large landslides using terrestrial remote sensing techniques. Natural Hazards and Earth System Sciences, 9(2), pp. 267-287.

Wakrow, R., and Chandler, J.H., 2008. A convergent image configuration for DEM extraction that minimises the systematic effects caused by an inaccurate lens model. Photogrammetric Record, 23(121), 6-18.

Walstra, J., Chandler, J.H., Dixon, N. and Dijkstra, T.A., 2004. Time for change - quantifying landslide evolution using historical aerial photographs and modern photogrammetric method', International Archives of the Photogrammetry, Remote Sensing and Spatial Information Sciences, Istanbul, Vol XXXIV, Part 4, pp 475-481.

Welch, R. and Jordan, T. R., 1983. Analytical non-metric close range photogrammetry monitoring stream channel erosion. Photogrammetric Engineering and Remote Sensing, 49(3), pp. 367-374.

Wickens, E. and Barton, N. R., 1971. The application of photogrammetry to the stability of excavated rock slopes. Photogrammetric Record, 7(37), pp. 46-54. 